$\therefore \because \therefore \therefore \quad$ III $\because 1486$

UCRL-93846

PREPRINT

\title{
FACILITIES AND TECHNIQUES FOR $X$-RAY DIAGNOSTIC CALIBRATION IN THE 100-eV TO 100-keV ENERGY RANGE
}

\author{
J. L. Gaines \\ F. J. Wittmayer
}

This paper was prepared for submittal to the Society for Photo-optical Instrumentation Engineers (SPIE) 30th Annual

International Technical Symposium on Optical and Optoelectronic Applied Sciences and Engineering, San Diego, California, August :7-22, 1986

June 1986

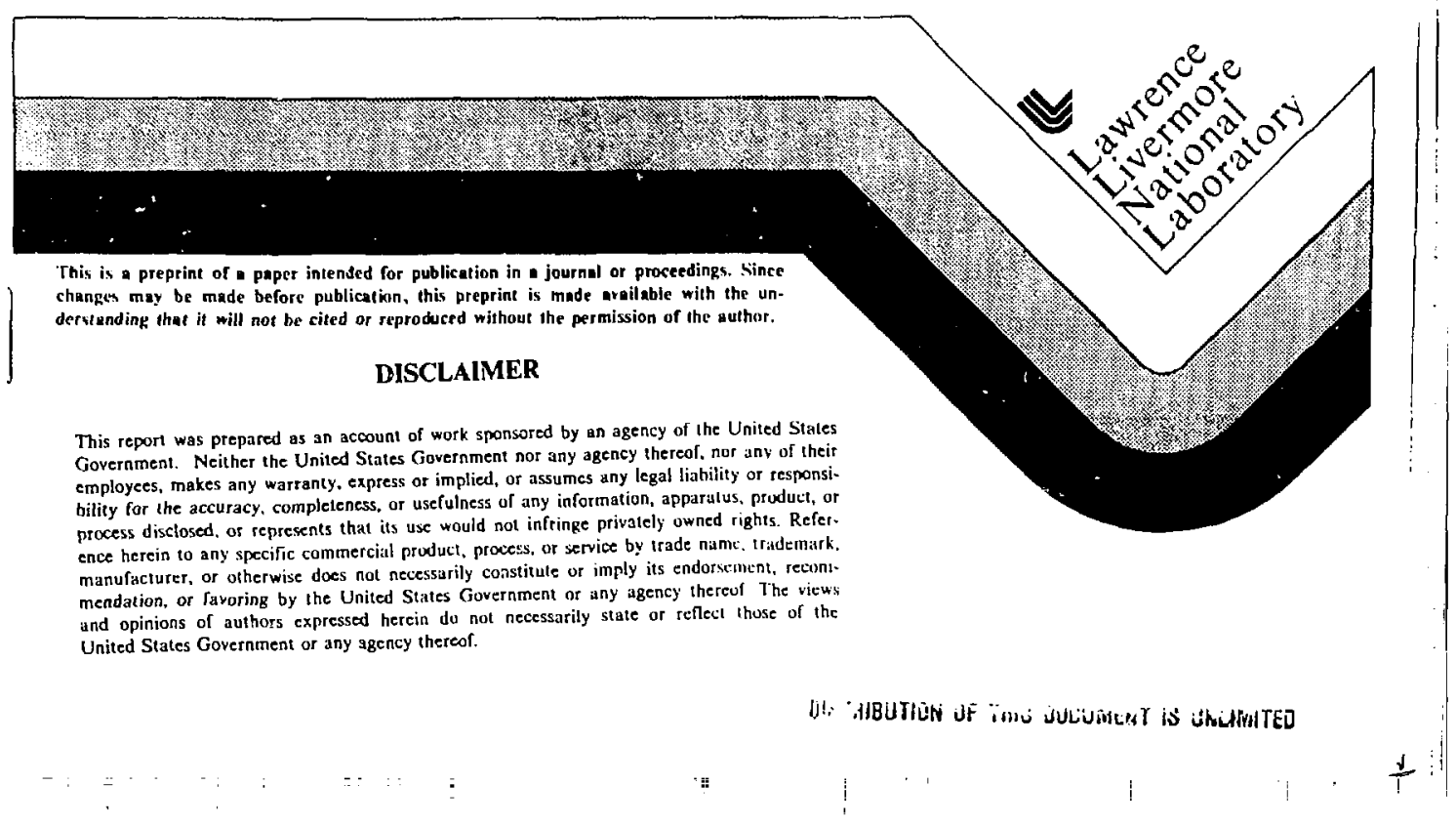




\section{Facilities and techniques for x-ray diagnostic calibration in the 100-cV to 100-keV energy range}

\section{J. L. Gaines and F. J. Wittmayer}

University of California, Lawrence Livermore National Laboratory Mail Stop 379, P.O. Box 808, Livermore, California 94550

\section{Abstract}

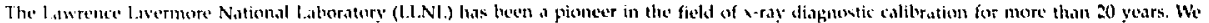

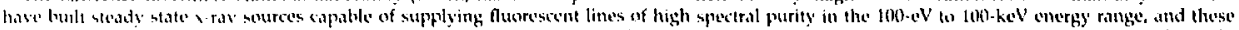

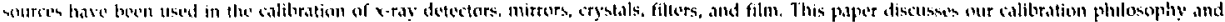

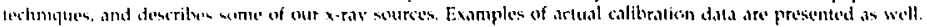

\section{Introduction}

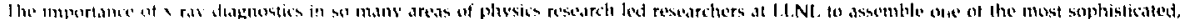

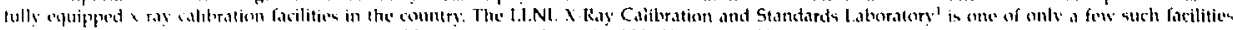

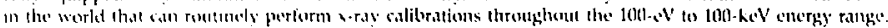

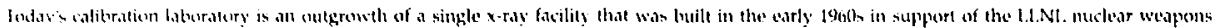

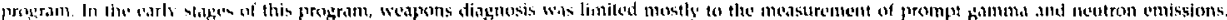

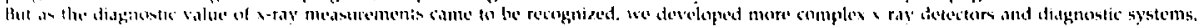

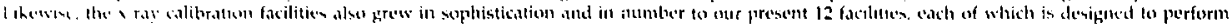

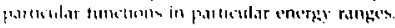

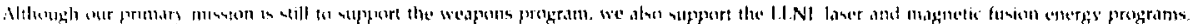

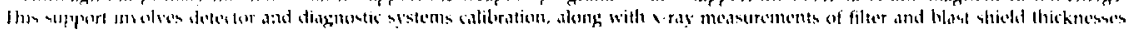

\section{Calibralion philosophy}

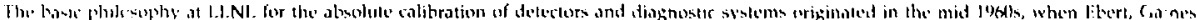

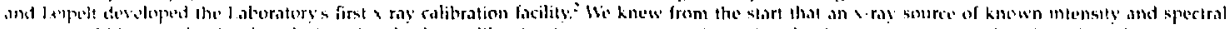

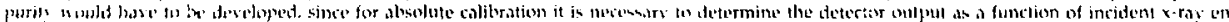

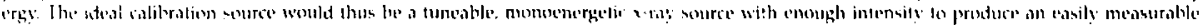

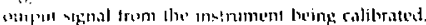

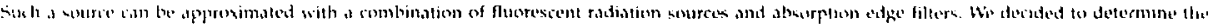

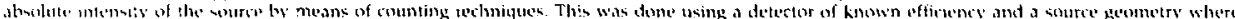

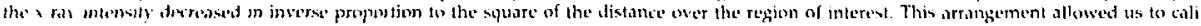

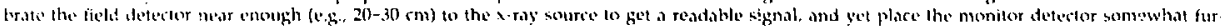

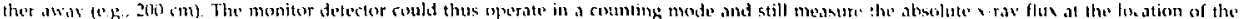
Ix]d S.lutior

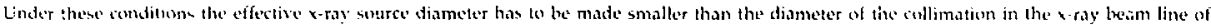

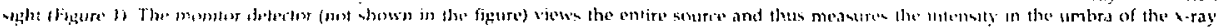

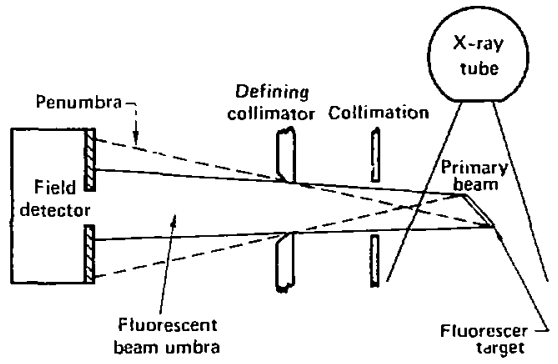

Figure 1 I.I.N1. calitration peomelry. The delector to he cilibrated (i.e., the field deterer) is nermally plared beiween $20-30 \mathrm{~cm}$ from the fluorescer target. and the monity detecter (not showe here) is roughly $200 \mathrm{~cm}$ away. The flucrescem beam untra is of uniform intensits. 
beam. Either the fjeld detector must intercept all of the x-rays coming through the defining collinator, or it must bo collimated in such a way that the collimator is within the umbrs of the $x$-ray heam. When eilher of these ronditicns is satisficd, Ihe $x$-ray nux measured by the monitur detecior can be correlated with the $x$-ray fux incident on the field detector.

Assuming a monoenergetic $x$-ray beam, the sensitivity of the delector can be calculated for a particular energy using the relation

$$
S=\left(\operatorname{le} \Lambda_{2} T r_{1}^{2}\right) /\left(N \Lambda_{1} F r i\right) ~ C / k e V
$$

where

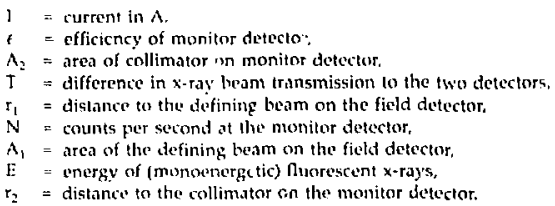

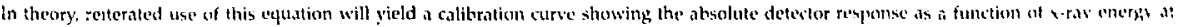

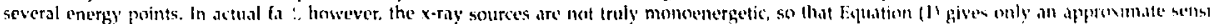
tiosty value. $A$ determina

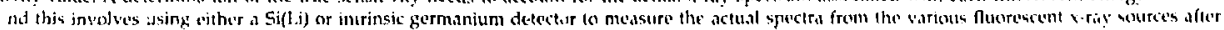

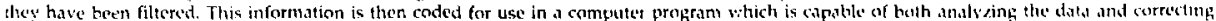

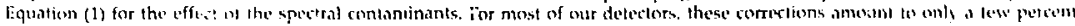

\section{X-ray sources}

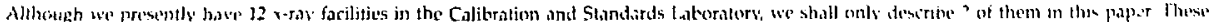

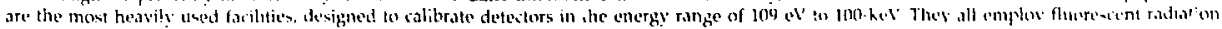

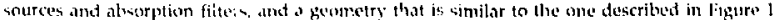

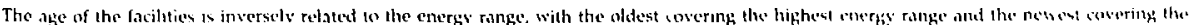

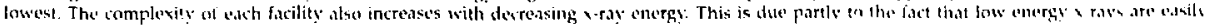

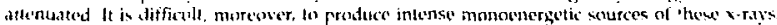

Photographs of whe three lacilitios ton le described are shown in ligures 2-4.

\section{High-energy facility}

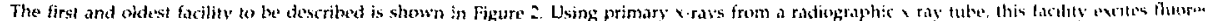

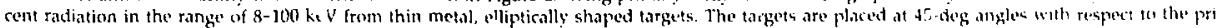
mary and the nuoreserent ray beam line of sight (sece liggure 1)

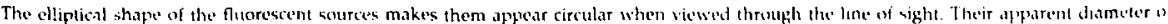

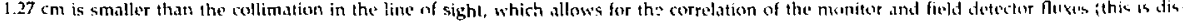
cussed above, umder the heading "Cabibration philosephy')

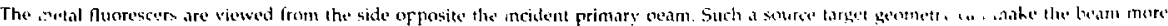

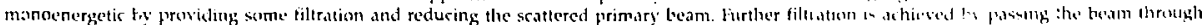

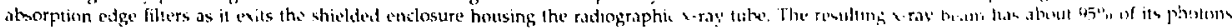

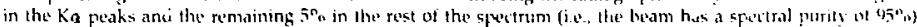

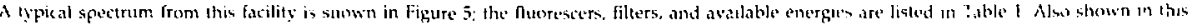

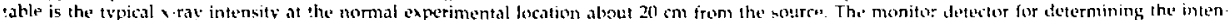

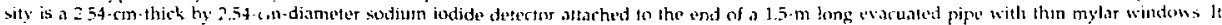
is collimated with a $0.07714-6 \mathrm{~m}$ diameter pinhole located aixut $20 \mathrm{~cm}$ from the source. The detectors lo he calilirated are insertedi in ile path of

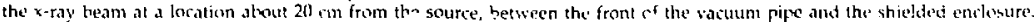

\section{LLw-energy facility}

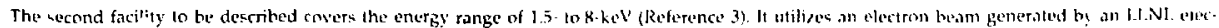
inn gun to excite one of nine avalable water-cooled targets.

This facility is shown in ligure 3. Il produces an x-ray beam of fuoresrent radiation as well as siome hremsstranlung when electrons from the „un strike the target. The linear $x$-ray target geometry ivas designed to reduce brenisstrahlung, si, lce, as inn he seen in figure 6 , $x$-rays are ohserved in the rearward direction, and hremsstrahlung is preferentially produced in a forward direction. 


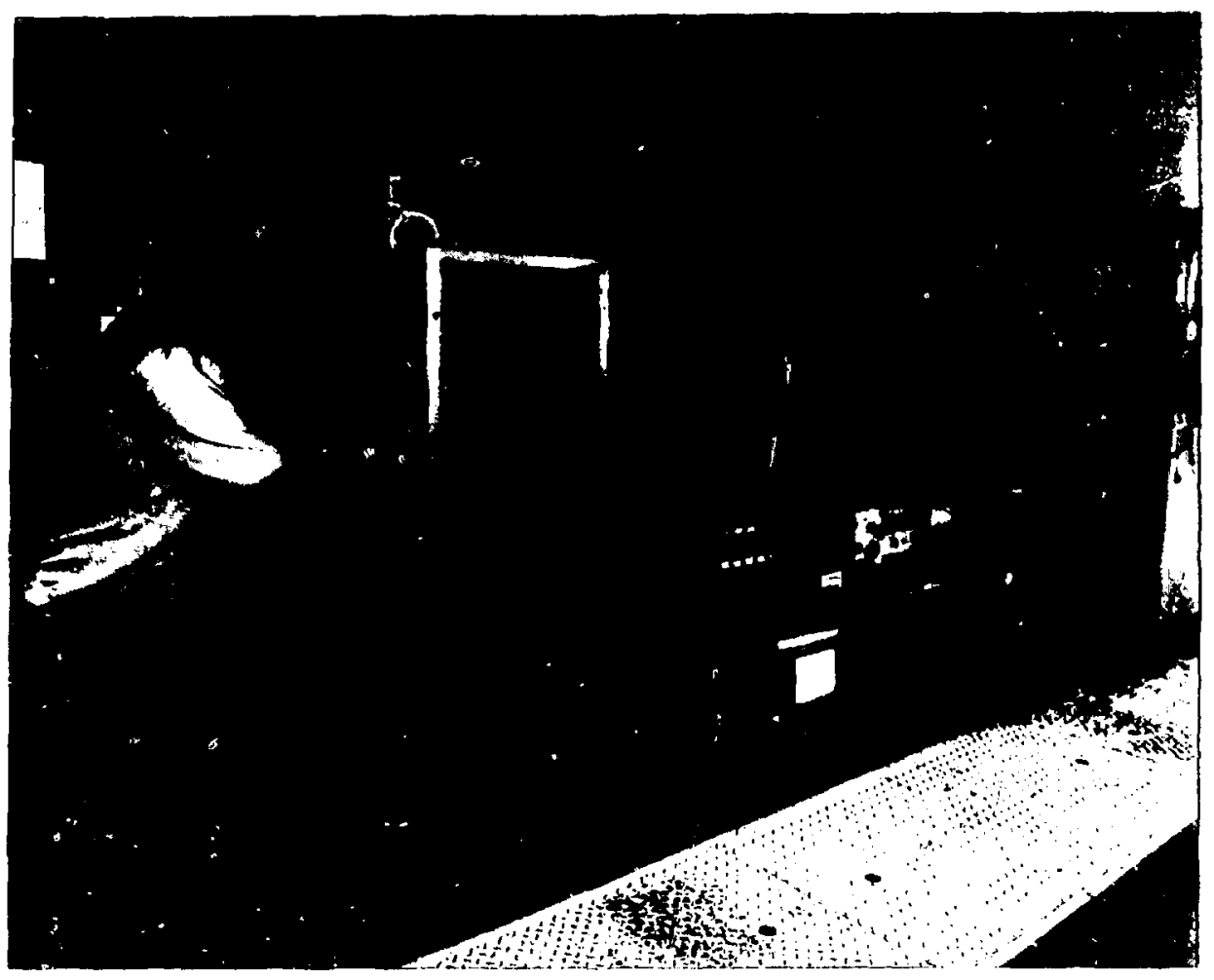

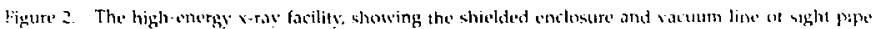

Tiathe 1. High-linergy Xikay lixility

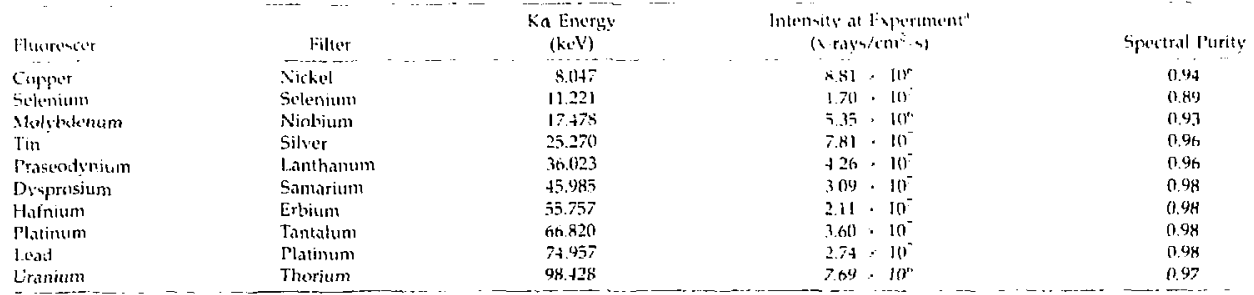

"The menitor detector bication is ahout $20 \mathrm{~cm}$ from the targal. 


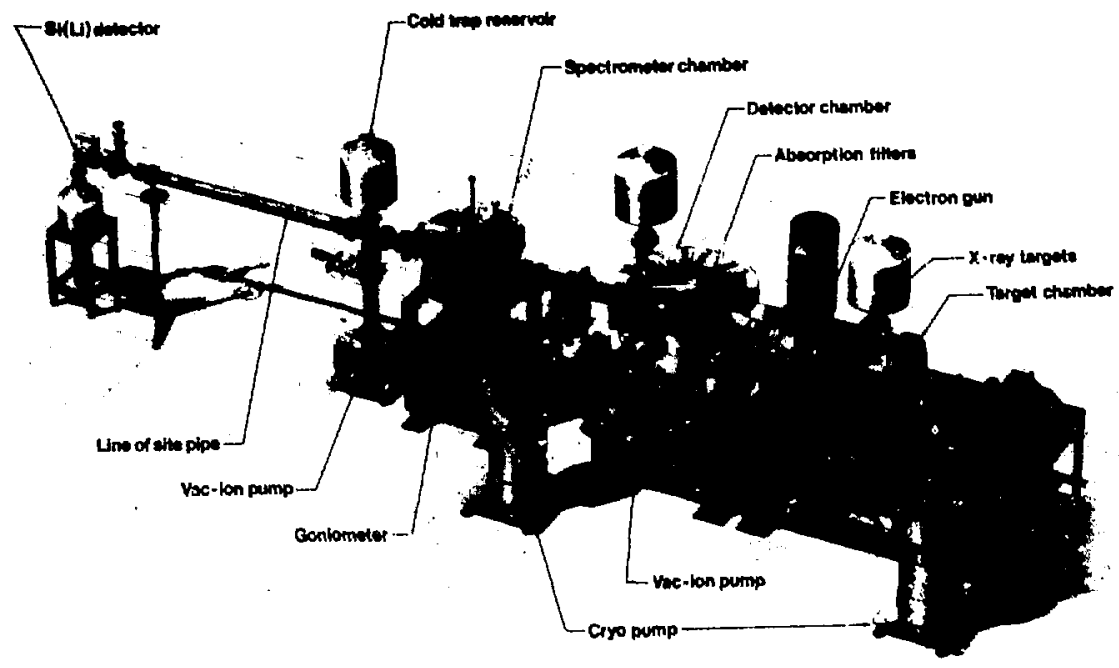

Figure 3. The low-bietgy y-roy facility:

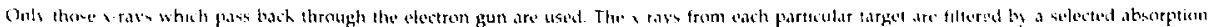

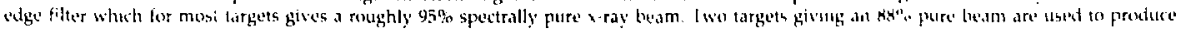
I.-shell characteristic $\times$ rays while the other, higher purity targets produce $K$-slicll $x$-rays.

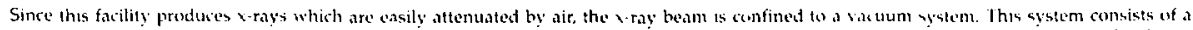

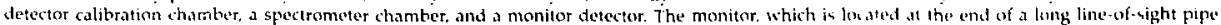

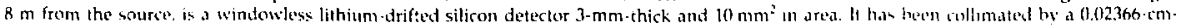
diameter collimatur.

Tahle 2 lists the various targets and energies available for this facility, as weall as the filtere used for cleuming up the upectro. Also listed are the typical $x$-ray intencities at the nor:nal experimental focation af aboul 60 rm.

\section{lon-accelerator subkilovolt facility (lonas)}

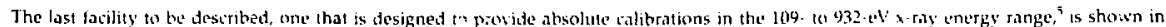
Figure 4 . This facility utilize protons to excite fluorescent $x$-rays from various sclertable targets. The advantage of :hts techaique is that the mass of the proton is much larger than that of an electron and therefore the bremsitrahlung production is greatly reduced. The source of the protons is an ior. arcelerator capadie of groviding a 2 -m $\mathrm{A}$ heam curent on the target at $300 \mathrm{kV}$. Niormal operaling paramerers, however, are now limited by the target cooling capacity to $250 \mathrm{hV}$ with a 0.5 . to $1.0-\mathrm{mA}$ heam curren:

The $x$-ray heam from the various sclectable targets can be observed at two locations, each at a 45 -deg angle with respect to the target. Depending on the targel material, this beam is then filtered by either a thin beryllium, thin carbon, or thin boron foil. The primary purpose of the foil is to stop the backscattered protons and neutral particles which are produced when protons strike th , target. In some cases (e.g., for the beryllit: $\pi$, boron, and carhon targets), these ibils can aiso help to clean up the spectra by solectively attenuating any low and high energy contamination relative 10 the fuorescerit peaks.

The monitor detector for determining the $\mathrm{x}$-ray intensity is a gas fow proportional counter. It is collinated by a 0.0256.em-diameter pinhale located in the detector calibra!..in chamber about $112 \mathrm{~cm}$ fron the x-ray source (see Figure 6). A spectrometer chanbel for calibrating crystals and mirrors is available for measuring the snectral purity of the $x$-ray beam. A windowless $S i(L)$ i) detector is also available for spectral examinations. Table 3 lists the targets and their average energies, the fluorescers, filters, and the heam intensities that are routinely available for this facility. 


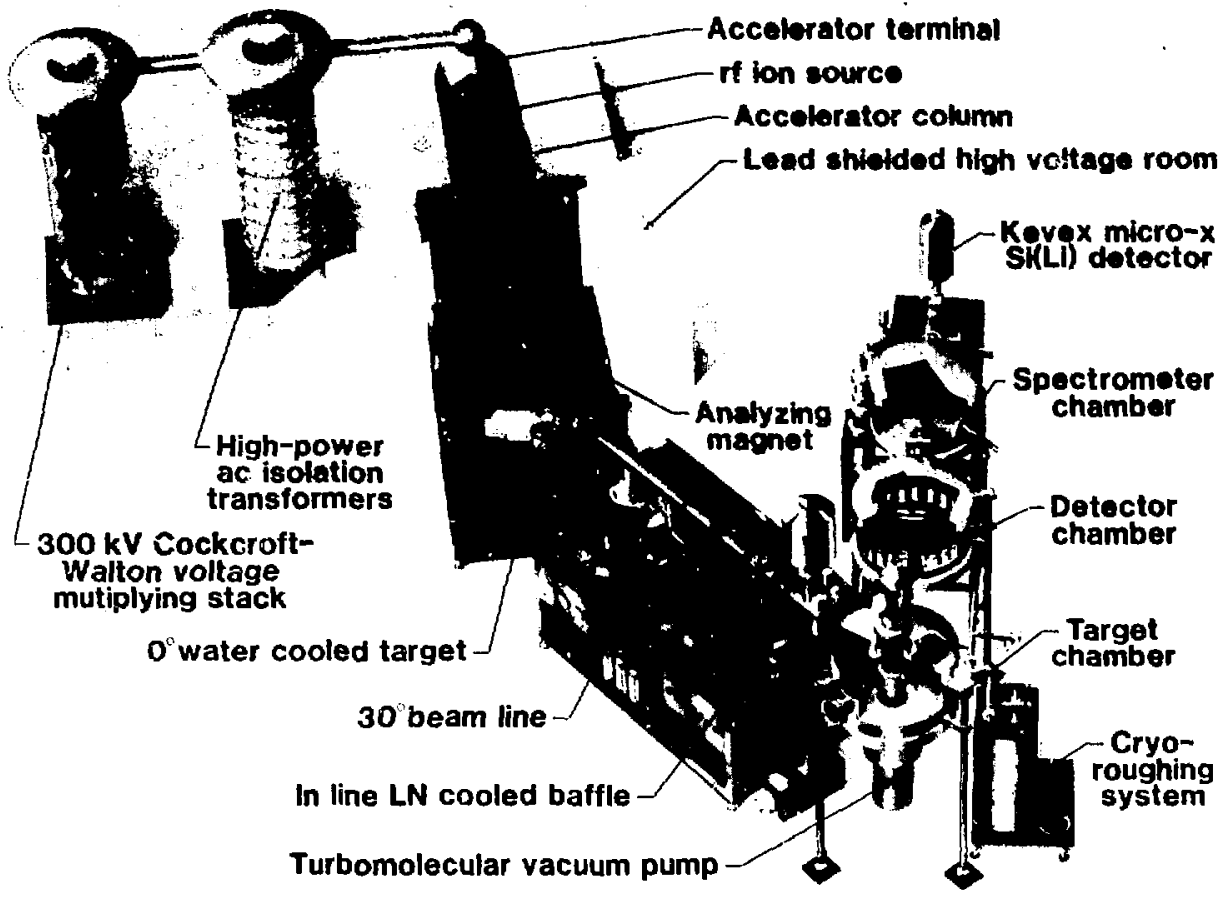




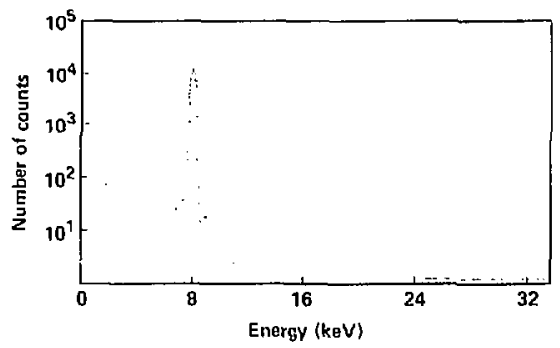

Figure 5. A typical spectrum for a copper fluorescer, seen through a nickel filter at the high-energy facility.

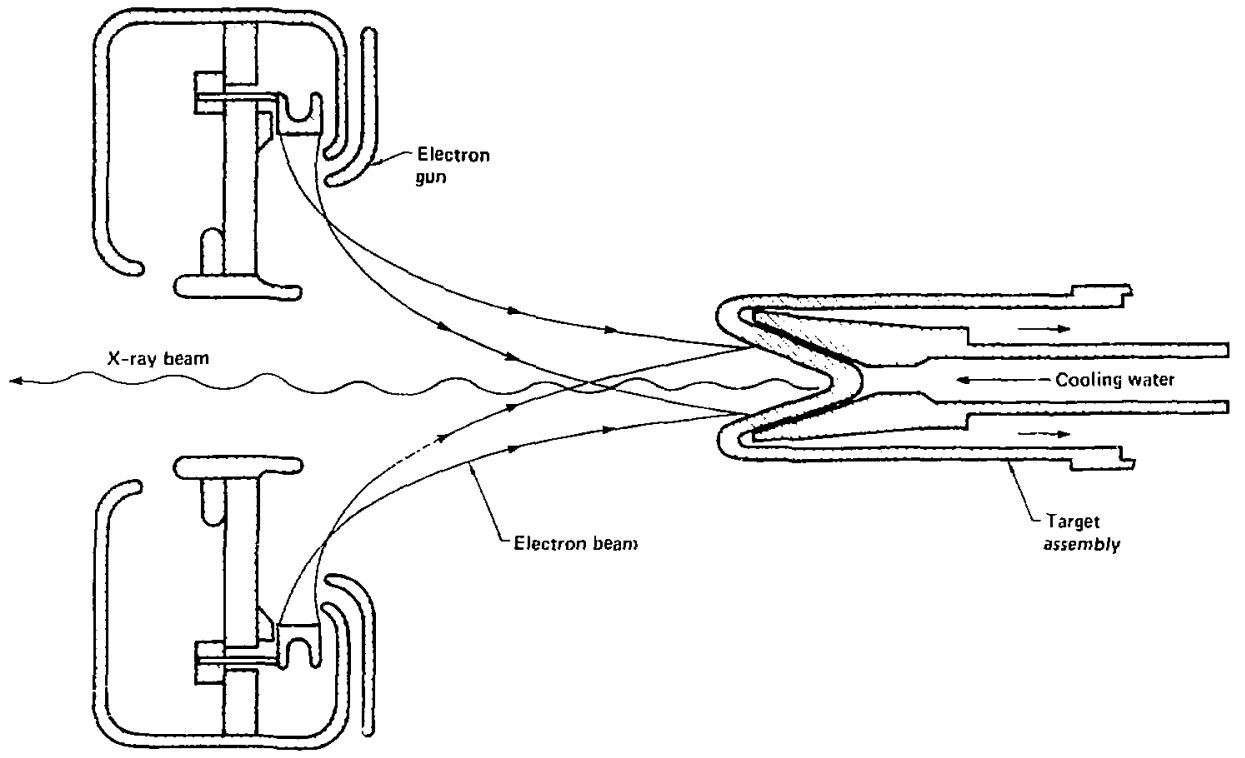

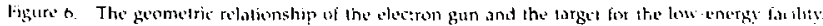


Table 2. Low Energy X.Ray Racility

\begin{tabular}{|c|c|c|c|c|}
\hline Fluarescer & Filter & $\begin{array}{l}\text { Ka Energy } \\
\text { (kev) }\end{array}$ & 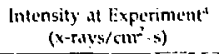 & Spectral ['urily \\
\hline Aluminum & Nluminum & 1.487 & $1 .+9 \times 10^{4}$ & 0.95 \\
\hline Zirconium & Yttrium & $2.042^{b}$ & $1.33 \times 10^{5}$ & 0.87 \\
\hline Silver & Rhodium & $2.984^{4}$ & $2.54 \times 10^{*}$ & 0.89 \\
\hline Scandium & Antimony & 4.090 & $1.49 \times 10^{5}$ & 0.94 \\
\hline Vanadiun & Tiıaniun & 4.952 & $1.0 .3 \times 10^{3}$ & 0.98 \\
\hline Manganese & Chromiun & 3.898 & $0.98 \cdot 10^{\circ}$ & 0.97 \\
\hline Cohili & Iron & 6.930 & $8.61,10^{\circ}$ & 0.98 \\
\hline Crpper & Nichis] & 8.047 & $1.73 \times 10$ & (1.98 \\
\hline
\end{tabular}

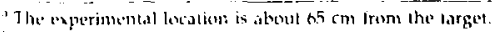

1.n entrens

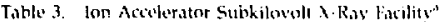

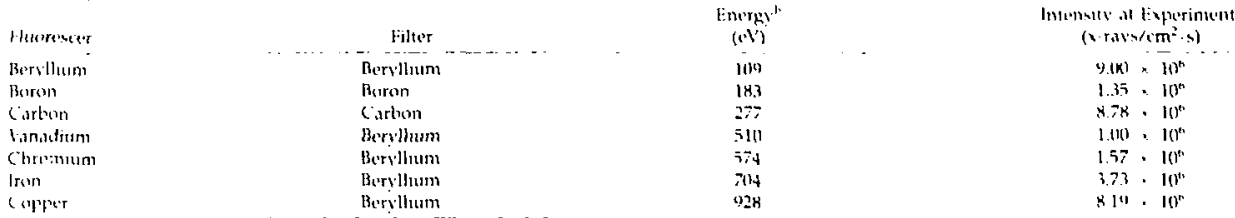

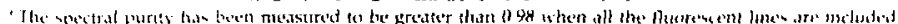

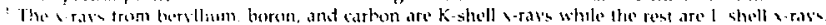

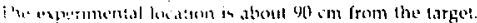

\section{Spectral measutements}

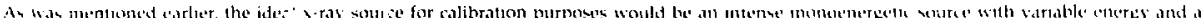

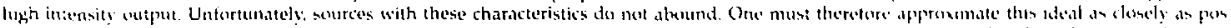

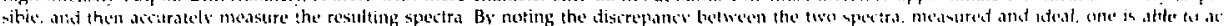
comel lor the verctral contaminants.

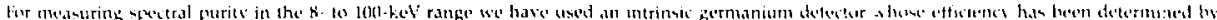

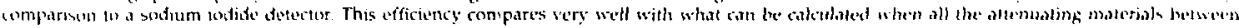

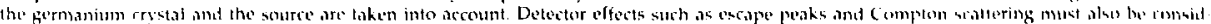

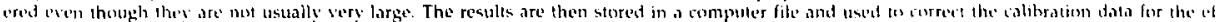

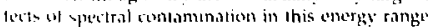

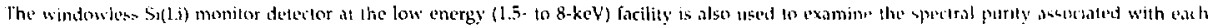

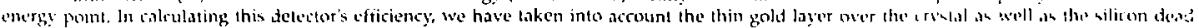

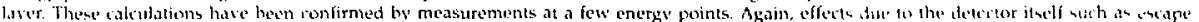

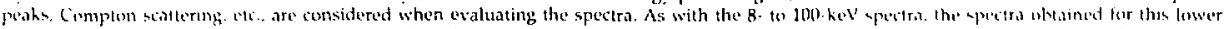

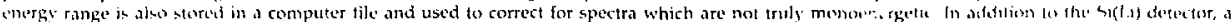
"rstal spectrometer an he used to examine the specta in much greater detail if necessary.

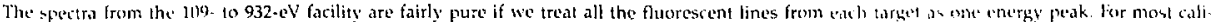

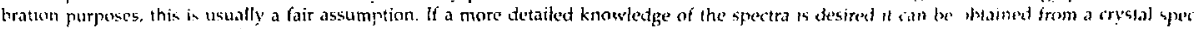
tromeler, which is an integral part of th" sistem.

Sime the spectro for this ultra-low-energy facility are sery pure, we are not now making any speretral currections. In addition to the crystal spee

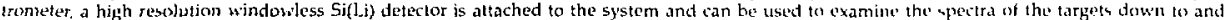
incluting carbon

\section{Absolute intensity measurements}

The key to making absolute calibrations is in determining the absolute intensity of the $x$-ray heam striking the instrument to te alibrated. We believe that the easiese way to do this is to actually count all the photons striking the device being calibrated. and then to use the measured spectral distribution in determining the number of photons at each energy: Such a procedure reoviti: a motutor detertor of knovn efficiency, prelerably a detector that is $100^{\circ}$ : efficient for all $x$-rays observed.

As described previously; for the 8- $10100-\mathrm{keV}$ facilily; a $2.54-\mathrm{cm}$-thick by $2.54-\mathrm{cm}$-diameter Na(I) deteclur counts the individeal yhutons in the $x$-ray beam. This detector is $100 \%$ efficient for the $x$-rays of interest (i.e., it absorbs all incident $x$-ravs), and needs only to be corrected for the eflects of the $0.0127 \cdot \mathrm{cm}$-thick beryllium and the $0.0001-\mathrm{cm}$-thick aluminum entrance wirdow: The nscape peak is not a problem since it gets counted along with ali the olher $x \cdot$ rays in the spectrum. 


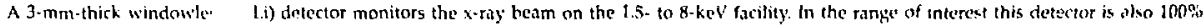
efficient, and the only necessary corrections are for the $150-A$ gold layer on the crystal and the 100 - A silienn deat loyer Since we are counting all the $x$-rays in the beam the escape peah presenls no problems.

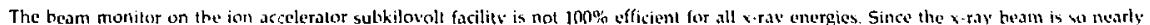
monoenergetic, hatvereer. we do not make spectrat corrections for this facility. All we have to kinow is the efficiency of the desector at the energy of

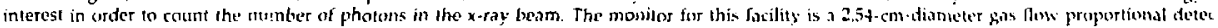

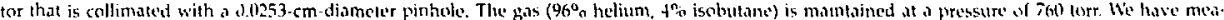
sured the efficiency of thin gas compared to P. 10 gas for comparisom with a calculated value. Agreement is guile goond when the measured trans

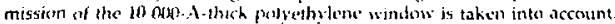

\section{Calibration techniques}

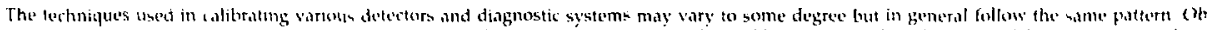

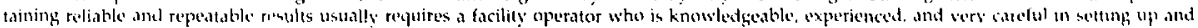

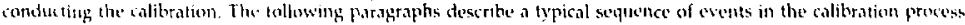

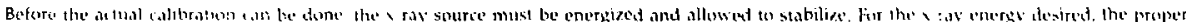

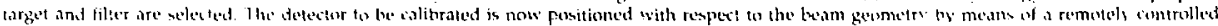

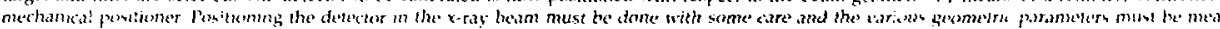

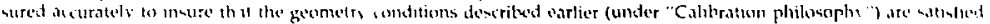

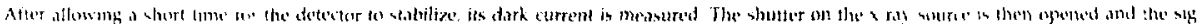

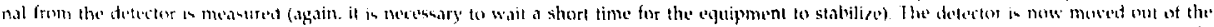

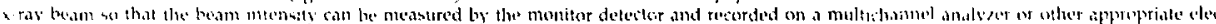

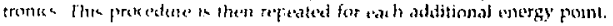

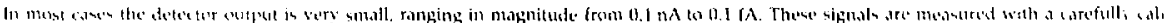
bromet abe:

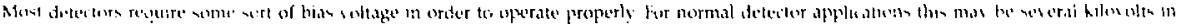

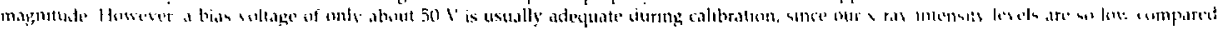

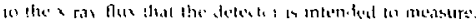

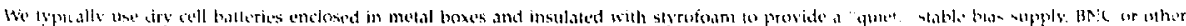

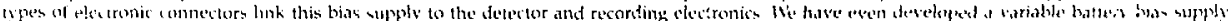

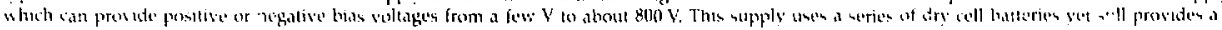
low nosise. low flakage cursent atable bias voltage.

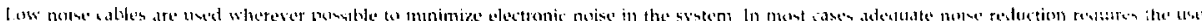

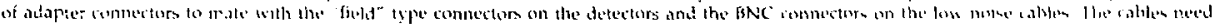

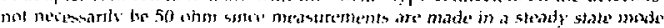

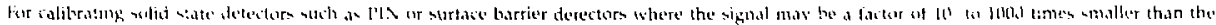

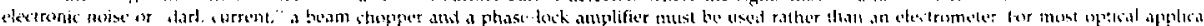

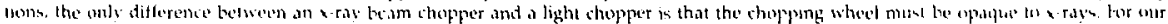

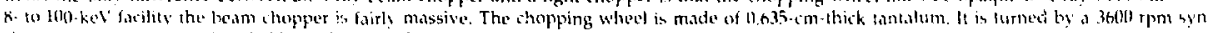

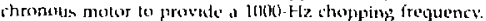

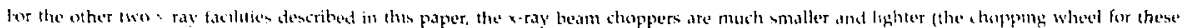

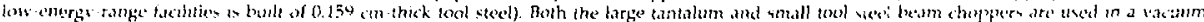

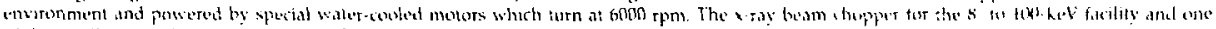

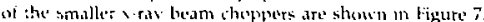

\section{Catibration projece activitics}

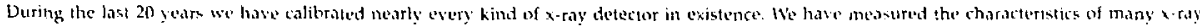

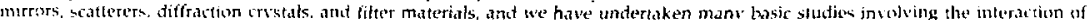

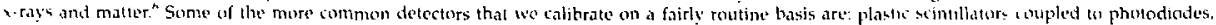

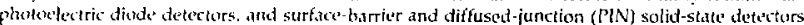

The calibration curve (stetwior sensitivity ss energy) for a $500-\mu$ depletion depth surface-harrier detector is shown in Figure 8 . The solid curve is hased on the calculated sensitivity while the points represent experimental data. For energy walues above 0.6 keV, the abreement between calculated and experimental sensitivity values is quile good. The lower energy portion of the curve is governed primarily by the aluminum entrance window inicknesis of the detector $\left(50 \mu \mathrm{g}^{\prime}\left(\mathrm{cm}^{2}\right)\right.$. while the ligher energy portion is infuenced hy the detector thickness itself $(500 \mu)$

Figure 9 shows the response of a 2.54 -cni-thick plastic scintillator (Pilot B) coupled to a photodiode (FW'lli $A$ ). This figure also show's the response of an sluminum cathode photoelearic diwde detector. Since this detertor was windowless, and since only the two lower energy calibration facilities provide the vacuum environment that such a detector requires for eperation, it was calibsated only up to $8 \mathrm{keV}$. 


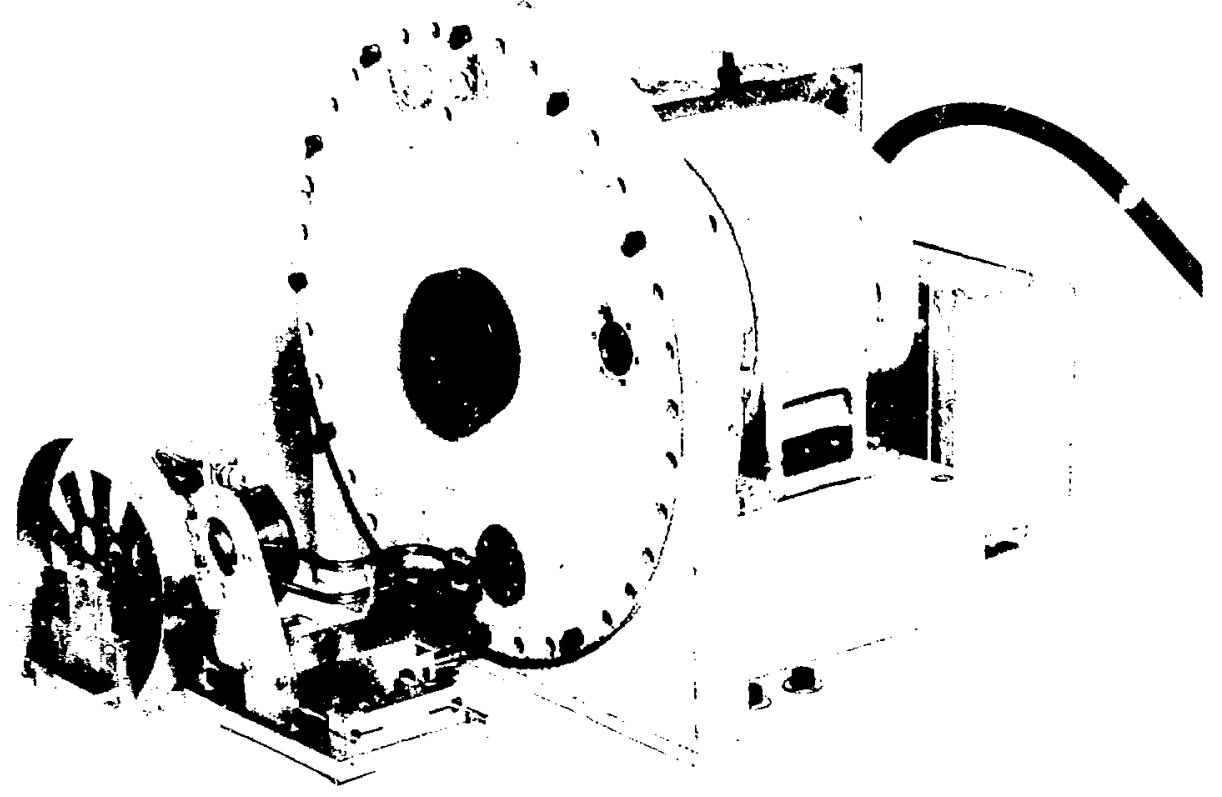

Figure 7. X-ray beam choppers for the high- and low-energy facilites. 


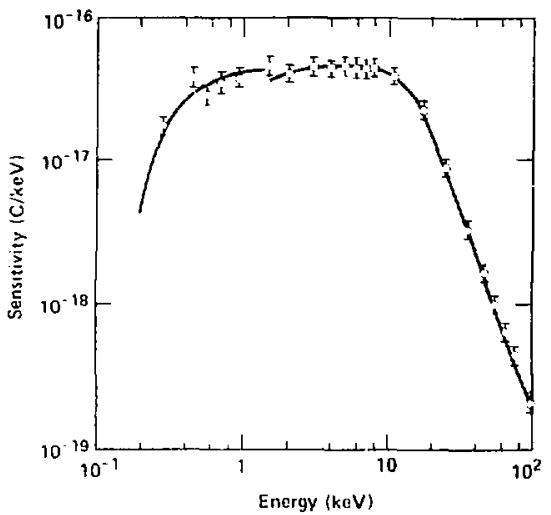

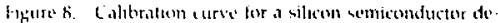

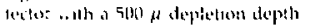

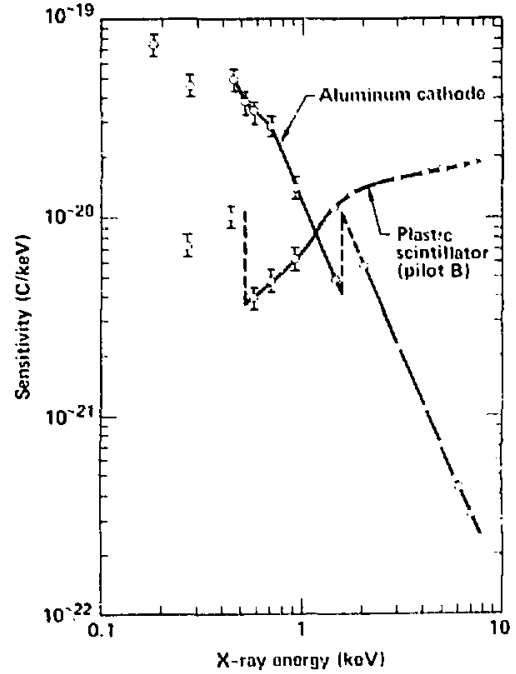

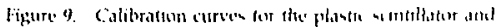
altminum sithoste stetecturs

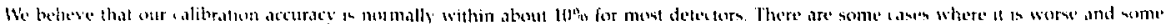

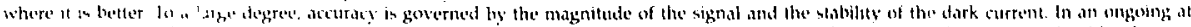

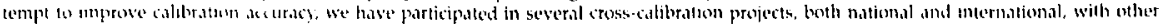
falionaturicin

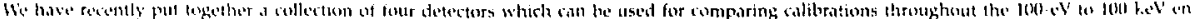

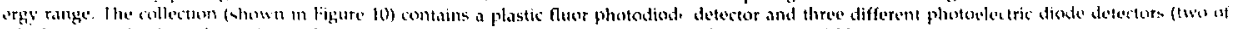

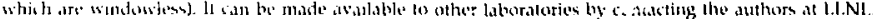

\section{Acknowledgunents}

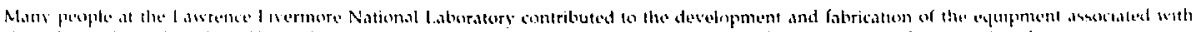

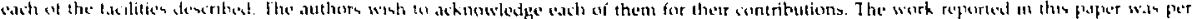

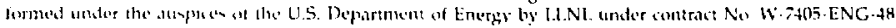

\section{References}

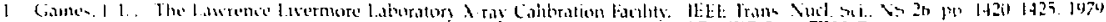

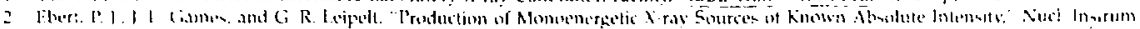

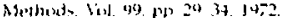

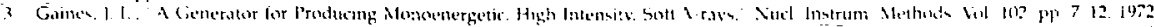

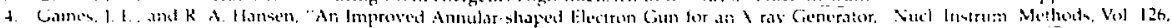

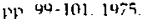

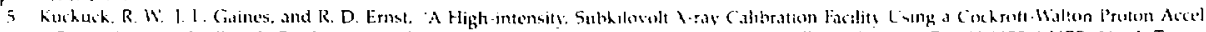

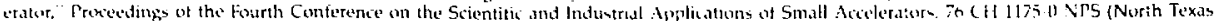

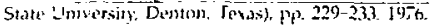

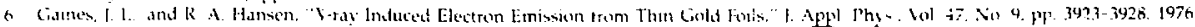




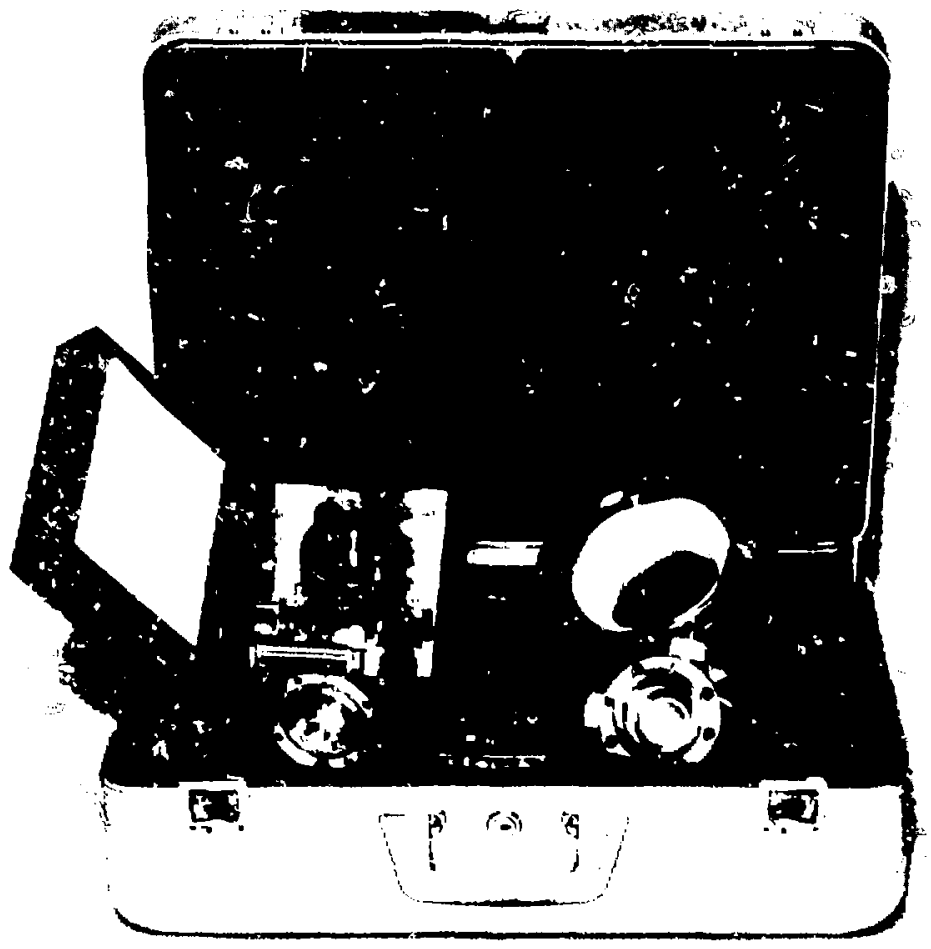

